This is an electronic reprint of the original article. This reprint may differ from the original in pagination and typographic detail.

Author(s): Kovala, Urpo

Title: Theories of Context, Theorizing Context

Year: $\quad 2014$

Version:

Please cite the original version:

Kovala, U. (2014). Theories of Context, Theorizing Context. Journal of Literary Theory, 8(1), 158-177. https://doi.org/10.1515/jlt-2014-0007

All material supplied via JYX is protected by copyright and other intellectual property rights, and duplication or sale of all or part of any of the repository collections is not permitted, except that material may be duplicated by you for your research use or educational purposes in electronic or print form. You must obtain permission for any other use. Electronic or print copies may not be offered, whether for sale or otherwise to anyone who is not an authorised user. 


\section{Urpo Kovala}

\section{Theories of Context, Theorizing Context}

Abstract: Theories of meaning, even outspokenly textualist ones, have always dealt with the question of relevant context as well, to some extent at least. In many fields of research, the idea of an encompassing theory of context has surfaced now and then, and there have also been actual attempts at such a theory, some of which are discussed in this article. At the same time the very concept of context is difficult in many ways. The term has been said to be one of the most widely used and widely abused terms in the humanities and social sciences. Brenda Dervin claims that »there is no term that is more often used, less often defined, and when defined defined so variously as context« (Dervin 1997, 13-14). More specifically, its analytical force suffers from the fact that it encompasses such a vast array of different elements. The many concepts that clearly deal with the relationship between text and context, however in a more limited or specific way, are one proof of this.

The focus in the article is on the project character of sexplicit theories of context - that is, theories which are framed and named as such, and where the concept of context is the key term or one of the key terms. The questions are: what kinds of projects are theories of context? What can they offer and can they surpass the limitations of their starting-points, not the least the very distinction between text and context? What kinds of models of context do these theories rely on? On what levels of analysis (ontology, epistemology, ethics...) are the theories operating and having consequences on? And what is the role of texts in theories of context? The theories discussed in more detail are the scontextualism` of Murray Krieger, Teun van Dijk's discourse analytic theory of context, radical contextualism represented by Lawrence Grossberg and others, and the contextualist worldhypothesis as described by philosopher Stephen C. Pepper.

Theories of context provide us with different solutions to the dichotomy problem. Krieger's solution is to bring in some aspects of the context e. g. by way of accounts of reading. A theorist of context may also resort to subsuming both text and context to a wider frame, for instance theory of action (Stierle), or introducing a mediating factor, for instance social cognition (van Dijk). A more radical solution to the problem is to conceptualize both texts and contexts as parts of networks with no obvious centre (Bennett, Hall, Grossberg). In such a configuration, the interpreting subject is also presented not as something apart but as part of a network. In the latter case especially, the concept of context gets heavily redefined. 
Even though the text-context distinction is increasingly questioned, it is also obvious that one cannot just do away with the distinction altogether, even by means of alternative conceptualisations. Interpretation is always interpretation of something, and dualism is hard to evade. This has been the problematic point for many scholars advocating a non-dualist approach to meaning. Giving up dualism means giving up some of the answers and perspectives it made possible. This idea of the inherent transitivity of interpretation is very probably deeply rooted in our general modes of perception and supported by both language and our everyday practices, as Stephen C. Pepper pointed out, so that our notions of meaning and interpretation, too, basically follow this assumption. And there is the additional fact that our tacit knowledge of the world lends ample support to this idea.

Why should we keep theorizing context, in spite of the many conceptual problems? First, as Lawrence Grossberg has pointed out, contexts are not »out there « to be picked up - instead, context is both starting point and end of analysis at the same time. Contexts are as much in need of conceptualization as texts. This is a good guiding principle regardless of one's discipline. Second, contexts are often invisible, especially when they are familiar contexts! They must be teased out, made visible, and this is facilitated by a theoretical contextualist framework. Third, even if we do not aim at and believe in the possibility of an overarching theory of context, we nevertheless cannot avoid dealing with tacit notions of context. These range from notions supported by language and our everyday perceptions and practices to taken-for-granted assumptions often supported by our institutions. This is the reason some scholars, for instance Ansgar Nünning, emphasize the need to theorize context: context theories are always »there«, and if we do not tackle them, they may and will have the kinds of influence on us that we would not like it to have.

What is the role of the text in different theories of context? For Murray Krieger, text is the definite centre. Textualism may be out of date ontologically, but the spower of the text that Krieger is interested in is something to be paid attention to by theories of context as well. Besides, another reason to keep text in the picture is that, after all, as Pepper and radical contextualists point out, text is context for its contexts! And even in a contextualist framework, bracketing a context has its value: in some cases it may be more fruitful to bypass the most obvious and salient contexts and take up counterintuitive ones, as for instance New Historicists prefer to do.

Is there still need and use for theory of context? Without necessarily aiming at an overarching, systematic grand theory, it is useful to think, with Stuart Hall, that a theory of context as such is not a goal, but to understand meaning-making, we must keep on theorizing context and contextuality.

Urpo Kovala: Research Centre for Contemporary Culture, Department of Art and Culture Studies, University of Jyväskylä, E-Mail: urpo.kovala@jyu.fi 


\section{Theory of Context - An Impossible Project?}

As there are multiple theories of text, why not have a theory of context as well? Such a goal has been expressed every now and then in different fields of research in the human sciences. In literary studies, for instance Teun A. van Dijk and Christine Richards have suggested that a "sound theory of literature« includes both a theory of the literary text and a theory of literary contexts (and an account of the relationship between the two) (van Dijk 1985, 245-247 and 1998, 22; Richards 1985, 261-263). Some scholars in other fields, too, have expressed the need for developing a worked out interdisciplinary theory of context (Bonß/ Hohlfeld/Kollek 1994, 447; Keesing 1972, 28). On this view, context and contextuality could provide a fruitful interdisciplinary field for the study of the specific nature of the production of meaning.

There have been actual attempts to formulate such a theory. Many linguists, such as Eugenio Coseriu, J. R. Firth, and recently Teun A. van Dijk, have planned or constructed theories of context. Karlheinz Stierle, literary scholar, proposed a theory of context embedded in a more general theory of action. In philosophy, Stephen C. Pepper laid down the principles of the contextualist world hypothesis. In addition to repeatedly addressing the text-context problematic indirectly, Michel Foucault dealt with it explicitly in his L'ordre du discours (1971), as did Jacques Derrida in Limited Inc (1988). Cultural studies as a whole can be seen as a decidedly contextual project and theorizing on context has been salient in that field.

Nevertheless, it must be said that the very concept of context is problematic in many ways. As Jeff Coulter (Coulter 1994, 689) has noted, the term is one of the most widely used and widely abused terms in the humanities and social sciences. In the same vein, Brenda Dervin claims that »there is no term that is more often used, less often defined, and when defined defined so variously as context « (Dervin 1997, 13-14; cf. van Dijk 2009, 1). More specifically, its analytical force suffers from the fact that it encompasses such a vast array of different elements (Bex 1992, 2; Cook 1990, 2). The many concepts that clearly cover context or some part of it are one proof of this. Such alternative concepts include »universe of discourse«, »dialogue«, »frame«, "paratext«, »mutual knowledge«, »horizon of expectations«, »schema«, »reading formation«, »rhizome«, and so on.

In this article, I shall not be dealing with the history of theories of context or of contextualist thinking, but will focus on the question of the nature of what I call here the sexplicit ` context theories and the challenges they face. Thus, a great number of important theories and approaches are left out of the focus. For instance the Bakhtinian-Voloshinovian approach to language is very much a theory of context ssans la lettre . Hermeneutics is a theory of or perspective on contextuality. Charles S. Peirce's theory of meaning can be seen as a systematic 
theory of context (Sowa 1997), and the same holds for Deleuzian ontology (Taira 2003), which has had considerable influence on contextualist approaches. This is just the beginning of a long list.

My focus in what follows is on the sexplicit theories of context - that is, the theories which are framed and named as such, and where the concept of context is the key term or one of the key terms. The questions are: What kinds of projects are theories of context? What can they offer and can they surpass the limitations of their starting-points, not the least the very distinction between text and context? What kinds of models of context do these theories rely on? On what levels of analysis (ontology, epistemology, phenomenology, methodology...) are the theories operating and having consequences? And what is the role of texts in theories of context?

There are actually rather few sexplicit s theories of context in the above, limited sense. The theories taken up below are the scontextualism ‘ of Murray Krieger, the linguistic-textual approaches of Eugenio Coseriu and Karlheinz Stierle, Teun van Dijk's discourse analytic theory of context, radical contextualism represented by Lawrence Grossberg and others, and the contextualist world-hypothesis as described by philosopher Stephen C. Pepper. Of these, I shall be looking in more detail at radical contextualism as well as the theories of Krieger, van Dijk and Pepper. In connection with each theory, I shall also, very briefly, look at other related theories which are not framed in terms of the notion of scontext discuss problems that theories of context tend to face and the solutions they offer.

\section{Irreducibility Thesis and its Tensions}

Perhaps somewhat surprisingly, I start with a scontextualist theory which today would certainly not be dubbed contextualist at all, namely Murray Krieger's theory of literary meaning. I use it as a backdrop against which to compare contextualist approaches proper, but at the same time it illustrates the problems involved in any dualist models of the text-context relationship. Basically, the theory subscribes to and elaborates on what could be called the irreducibility thesis. The thesis posits that literary meaning is, in essence, compositional meaning and that it is self-sufficient and can be detached from its (external) contexts without loss. Even though ambiguity and indeterminacy are essential aspects of literary meaning, as an early proponent of this view, William Empson, pointed out, the possible plural meanings are nevertheless a function of the text and its structures. Thus the »text in itself « very much exists for the proponents of the irreducibility thesis. The relevant context, in turn, is the internal context, which itself can be seen as a structure consisting of contexts of different levels (see Wellek/Warren 1961, 152-153). 
This view has its origins in T. E. Hulme and the notion of context proposed by I. A. Richards (see Rackin 1967). However, it has mainly been associated with New Criticism in general, and more recently with Murray Krieger's approach to interpretation. The view, as developed in New Criticism, was first dubbed »contextualism« by Murray Krieger, and was further elaborated to mitigate its clearly outdated aspects by Krieger himself, Lawrence B. Hyman, and Walter Sutton (see Hyman 1973 and 1975; Sutton 1958 and 1961).

Krieger subscribes to the New Critical notion of the literary work (»the poem«) as a closed, structured whole which provides the context for its own interpretation and which is self-sufficient. In his own words: "The claim that the poem is a tight, compelling, finally closed context - not reducible to any prior context - leads this theoretical approach to be properly termed >contextualism« (Krieger 1956, 17).

In addition to the purpose of delimiting the literary work, the irreducibility thesis thus aims at capturing the specific power of the literary work to apply familiar categories and to defamiliarize them at the same time. It is this latter aspect, the specific power of the text to create its own context, which the postNew-Critical proponents of the thesis, especially Murray Krieger and Lawrence W. Hyman, sought to »rescue«.

For Murray Krieger, however, the world-creating power of the text is not merely a power to evoke an interpretive frame of its own but also to exert a compelling power on the reader. It is this power of the text, not its ontology, that the selfsufficiency of the text is grounded on. Krieger is not interested in the smode of being of a literary work, as he himself has noted: »And questions about [the literary text's] ontological status I do not find interesting «. He describes his interest in the literary work as phenomenological rather than ontological (Iser 1986, 236-237.)

Krieger is saying - like Stanley Fish - that irreducibility has to do with ways of reading as well as with the ontology of the text. Self-sufficiency, for Krieger, not only has ontological significance but also, and above all, emotional and cultural sadded value which cannot be reduced to anything outside. "Reading right« involves permitting oneself to be overcome by the context of the text, by »surrendering one's own contexts to it " (Krieger 1974, 930). In a way, the text masters the reader; but then, the reader, according to Krieger, chooses to be overcome, and this surrender is not only willing but provisional, repeated with many different texts. Moreover, the reader engages in a kind of research in order to learn how best to treat this other context as if it were his or her own.

Krieger's later work is interesting because of its peculiar emphasis - which shows the influence of Hans Vaihinger's writings on the importance of fictional constructs in everyday thinking - on the illusionary character of critical constructions. This concern also extends to his view of the irreducibility of the literary text. In his Poetic Presence and Illusion (1979) the poetic presence is no longer 
objectual but phenomenological, born in the process of reading the work. Krieger rejects the grounding notion of the older versions of the irreducibility thesis, that of the "presence " of the literary work as an object having an ontological reality, as the result of »epistemological naïveté«. The presence of the work turns from a critical concept into a »myth « of the presence, a specific kind of an illusion. There are several influences behind this development in Krieger's work, the main ones probably being the Neo-Kantian emphasis on the constructive and "fictional« character of cognition, deconstruction's skeptical attitude towards ontological claims, and reception theory, especially its phenomenological branch.

For Krieger, literary criticism - just as literary discourse - is the sphere of the "as if «, where awareness of the fictionality of the myth of the poetic presence and self-sufficiency are suspended. Self-sufficiency - and along with it, unity - is reaffirmed, but in the form of a »necessary myth« or »necessary fiction«. Indeed, Krieger is abandoning the ontological justifications for the notion of the selfsufficiency of the literary text, but because of its wider significance, he is unwilling to give up the notion itself. He now conceives of the self-sufficiency of the poetic text as an enabling assumption which makes practical criticism - in its ideal mode possible. This stance, in fact, is shared by critics as different as Monroe C. Beardsley, E.D. Hirsch, and J. Hillis Miller! Although their definitions of meaning differ, their motivations for supporting the irreducibility thesis converge to some extent at least.

I am taking Krieger as a starting point for the reason that his position is a paradigmatic example of the tensions existing within the irreducibility theories as regards the challenge of contextualism. Awareness of the tensions leads Krieger to an amount of self-reflexivity and makes him take heed of contexts of reading and reception. He takes up the question of the levels of analysis, moving from ontology to phenomenology and, to some extent, epistemology. And his pronouncements on the "necessary fictions « of criticism also illustrate a common solution to these tensions, the difference being that in his case it is spelled out in an uncommonly self-reflexive and explicit fashion.

\section{From Dichotomy to Mediation}

Kriegerian contextualism started with the strict New Critical distinction between text and contexts, but later began to take into account ideas from other strands of thinking and to question the validity of the ontological foundations of the view. There have been approaches - or at least attempts at such - that have started with the question: as there are systematic theories of text, why are there not systematic theories of context as well? The starting point is the same as in Kriegerian contextualism, but the focus is on the other side of the text-context borderline. 
In linguistics, Eugenio Coseriu was the first to suggest and introduce a theory of context (Stierle 1980, 453-458). His aim was to elaborate on Saussurean linguistics by extending the analysis from system to context. Karlheinz Stierle (Stierle 1980), literary scholar, has also drafted an interdisciplinary theory of context, which would be a kind of theory of parole, in contrast with the emphasis on langue which had predominated much of linguistics. Stierle proposed such a theory as part of a more general theory of action.

This kind of endeavors still rely on a strict text-context distinction. An alternative would be to introduce a mediating concept. One such theory was launched by Dutch linguist Teun A. van Dijk. Throughout his extensive œuvre, van Dijk has stressed the contextuality of linguistic meaning and the need to develop a theory of context. After some thirty years, this project produced a theory of context, which was published in two closely interrelated books, Discourse and Context (2008) and Society and Discourse (2009). In the former, the writer outlines the basics of his theory of context, which is then utilized in the second volume.

Van Dijk strongly opposes what he calls a widespread misconception that social situations and their properties (e.g. the traditional background variables such as class, gender, age, etc.) exert direct and unmediated influence on language use (van Dijk 2009, vii). On the contrary, the very relation between society and discourse is indirect, mediated by the socially based but subjective definitions of communicative situations as they are construed and updated by the participants. According to van Dijk, indeed, social context can influence language use and thereby thinking through subjective definitions of the situation by participants only. These definitions are represented in what van Dijk calls »context models« - that is, mental models capturing the relevant features of social context. The theory thus introduces an element mediating between text and context, that of psychological mental models.

Van Dijk points out that this kind of sociocognitive framework is not popular in the social sciences, due to a gap between them and cognitive sciences. And that, in turn, is caused by what he calls a »regrettable reductionist ideology« of interactionism, which, he claims, shares the positivist starting-point of »observability" according to which talk and action are observable or socially available, while the allegedly individualistic minds of language users are not (van Dijk 2008, viii). According to van Dijk, however, his theory is compatible with integrational approaches in the social sciences - it links with them by making explicit what is usually taken for granted or expressed in vague terms. At the same time it extends context-free approaches to discourse by articulating a multidisciplinary framework that provides the missing link between discourse, cognition, and society. Writes van Dijk: »An explicit theory of context defined as mental models adds a fundamental dimension to our accounts of text and talk, ignored even in sophisticated formal approaches of discourse and conversation analyses.« (van Dijk 2009, 11) 
Van Dijk's theory seeks to incorporate the fact that in addition to elements of immediate situations, participants also model complex social macro-structures such as groups and organizations or abstract social structures such as social inequality. In that scheme, again, the sociocognitive theory aims to offer the missing interface. Furthermore, the theory takes heed of cultural variations in the use of context models.

As context is unlimited, the concept of context needs to be limited to refer to those properties of communicative situations that are relevant for the production and understanding of discourse (ibid., 4). Van Dijk's context theory did indeed introduce the notion of relevance as a key aspect in conceptualizing context. And relevance, in turn, is defined by the participants themselves. Van Dijk's context theory also strongly emphasizes the »reception" aspect, downplaying textual features. The text-context borderline remains distinct, but is mitigated by a mediating factor, cognitive context models.

\section{Radical Contextualism}

Theoretical takes on contextuality of meaning showing post-structuralist influences began to emerge from the 1980s onwards. The most salient one of these is the so-called radical contextualism based on the theory of articulation. This theory, which remains a prominent theory of meaning within cultural studies at present, is mainly known through the writings of Stuart Hall and Lawrence Grossberg (see e. g. Grossberg 1992; Hall 1982). The concept of articulation itself comes from Ernesto Laclau, from whom Stuart Hall borrowed it to analyse questions regarding race (Hall 1980; Laclau 1977). A standard definition of the concept is given by Laclau and Mouffe. They use it to refer to any practice that creates such a relation between elements that the identities of these elements are reformed in this articulatory process. The result is what they call discourse (Laclau/Mouffe 1985, 105).

In articulation, thus, the elements that are connected to produce a discourse are given a new meaning in the process. Their connection is non-necessary, "artificial «, and is usually accompanied by the disarticulation of old connections (Hall 1982, 82-83.). Indeed, articulations tend to manifest themselves, as Barthes pointed out about »myths«, as natural, commonsensical. Struggle over political support often involves the de- and rearticulation of political issues.

Articulation refers to the ongoing construction of more or less unstable relations between structures and practices. It involves the production of contexts, the ongoing effort by which particular practices are removed from and inserted into different structures of relationships, and the construction of a new set of relations within a 
shifting field of forces. Yet neither the components nor the context can be adequately described outside this set of relations; neither can be taken to pre-exist the other. Texts are not inserted into already existing contexts (inter-texts); rather, texts and contexts are articulated with and even incorporated into each other. In fact the difference between a text and its context, or a practice and a structure, is only a product of the level of abstraction at which one is operating.

Power is another concept central to the theory. According to Grossberg, wherever people and practices are organised around particular contradictions, there are multiple, differential relations of power involved. What he calls a conjunctural theory of power does not claim, however, that all such relations of power are equal, equally determining, or equally liveable; these questions are dependent upon an analysis of the specific, concrete conjuncture (Grossberg 1993, 53). Besides, as Foucault has reminded us, there are multiple forms of resistance and power.

Thus, articulation theory suggests both a radical reconceptualization of context and a particular and distinctive new interpretive strategy. The task it suggests for the cultural critic is a profoundly contextualist one: not merely to seek to identify the objective context which a particular text is rooted in, but to (re)construct the context - which can never be centred around any single text or practice - of a particular (e. g. ideological) field, in terms of how it is articulated, both internally and externally, to form specific relations. That act of construction is always the site of contradiction and struggle. Sensitivity to power relations is perhaps the main feature that distinguishes articulation theory from any other radically contextualist theory - such as that of Stephen C. Pepper, to be discussed below.

And finally articulation theory acknowledges its own articulation of the conjuncture which it analyses (Grossberg 2000, 43-47). This is the aspect that has been neglected in many theories of context. At the same time it is one which is very difficult to keep in mind and especially to take into account when performing one's analyses.

In all audience studies and cultural studies, the need to contextualise the research object is foregrounded. The differences emerge when we ask which contexts are most important. In short, the focus has shifted from influences and determinants to the embeddedness of cultural products. Speaking of audience studies, Ien Ang writes:

It is precisely the idea of profound embeddedness of television consumption (and of media consumption in general) in everyday life, and therefore its irreducible heterogeneity and dynamic complexity, that has been a central emphasis within culturalist audience studies, although the epistemological bearings of this emphasis, which amount to a form of radical contextualism, are not always thoroughly understood.

(Ang 1996, 69) 
For radical contextualism both »television« and "audience» are fundamentally indeterminate categories: it is impossible to tell a priori which possible meanings and characteristics these categories acquire in any specific situation in which people engage in television consumption. In any variety of textualist foundationalism, such situational factors would count as irrelevant. In radical contextualism, instead, meanings exist only as specific meanings in particular conjunctures. Stuart Hall has expressed the consequences of this emphasis as follows:

We are all, in our heads, several different audiences at once, and can be constituted as such by different programmes. We have the capacity to deploy different levels and modes of attention, to mobilize different competencies in our viewing. At different times of the day, for different family members, different patterns of viewing have different ssaliences«. Here the monolithic conceptions of viewer, the audience or of television itself have been displaced - one hopes forever - before the new emphasis on difference and variation.

(Hall 1986, 10)

Here Hall, as Ien Ang has noted, pushes to their limits the notions of multiplicity, indeterminacy, and heterogeneity that underlie radical contextualism (Ang 1996, 73). Indeed, this kind of radical contextualism is not far from sliding into an unstoppable dispersal of the notions of, say, reader or audience, text, context, and meaning. This would be a problem not only theoretically and in view of the goal of the analysis, but also methodologically. A project that would attempt to take into consideration the whole contextual horizon in which heterogeneous instances of media consumption acquire particular shape, significance and effectiveness would be exhausting, to say the least, and impossible in practice. As Ang aptly comments: "If not held in check, awareness of the infinity of intercontextuality could lead to contextualization gone mad! «(Ang 1996, 73)

Radical contextualism based on the theory of articulation does not stop here, because that would mean admitting that there is only difference and variation, and that the scholar interested in the meanings of cultural offerings can only observe and report that variation. This brings us to the question of the levels of analysis. For this type of radical contextualism, the epistemological and ontological considerations are bound to be insufficient or even counterproductive as guiding principles in choosing the appropriate conceptual framework with which to stop this slide into contextualization gone mad, because from an epistemological perspective all contexts relate to each other, even though it is easy to picture concrete cases where not all contexts are alike or equally important. It is within particular contexts of research - and this includes such things as the goals, policies, and positions of researchers - that it is possible meaningfully to decide which contexts we wish to foreground as particularly relevant, and which ones could, for the moment, »in this particular conjuncture«, be left unexplored. Even 
though we cannot justify our interpretations by means of any foundational criteria, we must and do resort to what Hall calls arbitrary closure in order to interpret anything (see Hall 1987, 45).

Here I should like to stress that specificity in this connection does not equal particularism. What is specific in the process of meaning production is - can be seen as - representative of or an aspect of something that is general. Thus, genderspecific reading, as should be obvious in our context by now - is not something a priori personal and irrelevant. And this holds for many other »background variables« as well.

This leads us to the question of how specificity in radical contextualism should be understood. In the words of Lawrence Grossberg, meaning is always conjunctural, in the sense that it emerges in the process of articulation of texts and contexts at a specific time and place (Grossberg 1993, 53-55). But what could be called the opposite of the particular, the general, enters this conjuncture as well. The particular is individual, while the specific is the fusion of the individual and the general.

For radical contextualism, meanings cannot be decided on outside of the multidimensional intersubjective networks and concrete contextual settings in which the object of inquiry is inserted and made to mean (Ang 1996, 70). Therefore, context is neither something surrounding the object of inquiry nor something to which the object is related. Instead, it is a configuration of texts and contexts, and of various levels and perspectives. Lawrence Grossberg argues that contemporary theory too often treats contexts as the beginning of analysis, as a background which exists independently of the object of inquiry, and which therefore can be taken for granted. For articulation theory, it is the background that actually articulates the focus (Grossberg 1992, 54). As Grossberg puts it in an oft-quoted passage:

The context is never a stable object of study. It is only available at the end of the analysis; it is the most difficult sthing « to get hold of, and the task is made even more difficult when the analyst is located in the context which he or she is fabricating. Articulation becomes a constant practice of replacing oneself, in specific ways, into the contexts that are available for rearticulation.

(Grossberg 1992, 55-56)

The definition of context developed in this brand of radical contextualism clearly comes close to - and has indeed drawn on - Gilles Deleuze and Félix Guattari's conception of rhizome. Deleuze and Guattari propose our objects of inquiry to be rethought as assemblages of heterogeneous elements which have no centre and which are constantly developing in different directions. The concept of the rhizome, too, emphasises the importance of specificity and interconnection. However, it also strongly repudiates unity and identity. Deleuze and Guattari 
claim that »there are no points or positions in a rhizome, as there are in a structure, a tree, a root. There are only lines [...]. Every multiplicity is flat in that it fills out and occupies all its dimensions« (Deleuze/Guattari 1981, 54).

Finally let us look at yet another position from which the independence of textual meaning has been questioned. That stance, which could be called a cultural materialist position, can be well illustrated by the writings of Tony Bennett. During his long career, he has both launched an extensive critique of the notion of stext itself $\triangleleft$ as an obsolete metaphysical construct and the very distinction between text and context, while sketching an alternative account that evades the notions altogether. From his book Formalism and Marxism (1979) onwards, Bennett has pursued a systematic critique of the notion of the autonomous »text in itself «. His main thesis is that the notion not only is invalid as a thesis about the relationship of text and context, but, more significantly, it is a heavily ideological notion. For him, it carries with it a »metaphysics of the text «. With this Bennett refers to a notion of the text as a "ghostly existence» behind the variant forms in which it exists historically. For Krieger, the »text in itself « was a necessary fiction, but for Bennett, such fictions tend to have "disabling consequences elsewhere«, carrying on an idealistic legacy (Bennett 1984, 120-121).

To avoid the dichotomies between text and context, subject and object, Bennett has coined the concept of reading formation. By this he means an entity covering and cutting through author and reader, text, and social and cultural context. A significant aspect of the reading formation is the machinery of mediation acting upon the texts in question. Bennett and Janet Woollacott, in Bond and Beyond. The Political Career of a Popular Hero (1987), set out to look for the reasons for the popularity of the character of James Bond. The topic necessarily foregrounds the fact that one cannot limit oneself to an analysis of the Ian Fleming books to understand the phenomenon. And it is also natural that the authors approach their topic from various angles. These include the production and distribution of the books and films, the evolutions of the character of Bond through them, as well as what they call »inter-textuality«. By this concept they refer to the social organisation of the relations between texts within specific conditions of reading (Bennett/Woollacott 1987, 44-45).

These various relations are then organised in specific ways, and it is to these ways Bennett and Woollacott refer with the concept of reading formation. Its significance is in that it enables a radically historical conception of text as nondetachable from the reading act and of reading as constitutive of the text in a strong sense. Thus, following Foucault, Bennett is trying to capture the network of determinations which is constitutive of readers, texts, and what appear as various contexts. While Grossberg and other proponents of articulation theory 
retain the notion of context, redefining it, Bennett and Woollacott turn it down altogether as a key concept and resort to an alternative conceptualization.

\section{Context as Process: Stephen C. Pepper}

At this point I should like to take up an older theory of context that in fact takes this extension of context to the extreme. I have in mind Stephen C. Pepper's variety of contextualism, first sketched in his book World Hypotheses (1942). Pepper outlines four distinct »world hypotheses«, formism, organicism, mechanism, and contextualism. Of these, contextualism is obviously the focus of Pepper's analysis, even though he points out that these world hypotheses necessarily overlap. The root metaphor for contextualism, according to Pepper, is the "historic event «. For the contextualist, everything in the world consists of such events. Since any event, however, is rich in detail, concrete, and a complex of intertwined and interconnected features, there is always, according to the contextualist, a degree of arbitrariness in selecting one feature instead of another. In addition, novelty is an important feature for the contextualist, so that many predominant features may not be universal. This necessitates an enhanced attention to the case at hand (Pepper 1966, 232-234.).

The other central category of Pepperian contextualism is change. For the contextualist, change is a fundamental principle in reality which precludes the existence of any unchangeable structures (ibid., 234-235). These features, of course, are not unknown in other world theories, either. Contextualism just holds to them systematically and takes them to the extreme. It must be noted, however, that the contextualist is, according to Pepper, constantly threatened with evidence for permanent structures in reality, and is on the verge of falling back upon either the underlying mechanistic structures or the overarching integrations of organicism (ibid., 235, 278-279.)

The theory thus offers an accentuated process perspective to objects of inquiry, which it sees as changing events instead of structures. But it offers a process perspective to research as well; for a contextualist, there is no final or complete analysis of anything. Pepper explains this as follows:

The reason for this is that what is analyzed is categorically an event, and the analysis of an event consists in the exhibition of its texture, and the exhibition of its texture is the discrimination of its strands, and the full discrimination of its strands is the exhibition of other features in the context of the one being analyzed - textures from which the strands of the texture being analyzed gain part of their quality. In the extended analysis of any event we presently find ourselves in the context of that event, and so on from event to event as 
long as we wish to go, which would be forever or until we got tired. [...] A bottom is thus never reached. For the support of every texture lies in its context. This support is as extensive as you wish, but you never reach the end of it.

(ibid., 249-250)

Pepper shares with Jacques Derrida the idea of the endless regress of meaning. And both in fact argue that as there can be no final meaning, such regress is inevitable. In addition, Pepper claims, there are many equally productive ways of analysing an event, depending simply on which strands one follows from the event into its context. The choice of strand is significant: for the contextualist, serious analysis is either directly or indirectly practical, it has an end and a direction determining the relevance of the choice. There is no importance in analysis just for the sake of analysis (ibid., 250-251). Here it is easy to detect the pragmaticist affiliation of Pepperian contextualism; on the other hand, Pepper distances himself from the paradigmatic pragmaticist ideology, the assumptions of which he seems to have in mind when talking of a specific stance within contextualism, dubbing it »instrumentalism« (ibid., 236, 250).

Pepperian contextualism starts with the particular: it »works from the present event outwards«. It is definite about the present event, but less and less definite about the wider structure of the world. It is willing to speculate about these structures, but leaves the back door open. As Pepper puts it: »But if anyone pushes a contextualist hard, he retires into his given event and the direct verification he makes from it.« (ibid., 278)

The distinction between text and context can be found in Pepperian contextualism, too, but in an extremely diluted form. The main categories through which Pepper sets out to describe contextualism are quality and texture. These categories of every historical event are intertwined in that the quality of a given event is its "intuited wholeness « or total character, while the texture consists of the details and relations which make up that character or quality. Thus, holism occupies a central position in Pepperian contextualism: it denies that a whole is nothing but the sum of its parts. Like radical contextualism, the approach thus does not exactly amount to particularism; but one must add that it may appear so due to its insistence on the individual historical event.

As subcategories of quality, Pepper identifies "spread«, »change», and »fusion«. Spread refers to the way the present moment reaches both backward and forward, taking in both future and past meanings of the event in focus. Change, obviously, refers to the continuous evolution of reality; a repeated event is not the same event any more. This change, according to Pepper, "goes on continuously and never stops. It is a categorical feature of all events; and, since on this world theory all the world is events, all the world is continuously changing in this manner«. Pepper even suggests that in order to do justice to this radical event 
nature of reality, one should use only verbs! (ibid., 232-235) Fusion, in turn, refers to the varying degree to which the qualities of the details merge in the quality of the whole. Thus, it involves qualitative simplification and organisation. Fusion may be more or less relaxed, but some fusion must remain: »otherwise the event would break apart and we should have not a single event, but two quite unconnected events« (ibid., 235-245).

Texture is made up of the subcategories of "strand « and »context«. These two are, again, intertwined in that the texture of an event is made up of strands, contributing details, which at the same time reach out into the context of that event and imbue the texture with some of the quality of the context. In Pepper's account of contextualism, thus, one cannot draw a sharp line between texture, strand, and context (ibid., 48). The concepts merge into each other, which is of course the very point of this brand of contextualism.

The systematicity of Pepperian contextualism is particularly interesting in that it leads to quite surprising conclusions concerning the role of the text. First of all, it allows for competing world theories and approaches, for instance formism and organicism, which, in spite of disciplinary differences, can easily be detected as having had different statuses in the history of the human sciences. Pepper points out that although contextualism acknowledges disorder, this world view, if pursued radically and consistently, must incorporate order as well! Pepper writes: »But, so to speak, disorder is a categorical feature of contextualism, and so radically so that it must not even exclude order.« (ibid., 234)

Secondly, another consequence of this kind of systematic and radical contextualism would be that the contexts of different genres of texts display their own specificities, which must be kept within view and accounted for. I should like to emphasise that this is a logical consequence of the extreme contextualist position, not for instance a compromise between the requirements of cultural studies or other kinds of contextualism on the one hand, and textualist approaches on the other.

The theory thus problematizes the dichotomy between text and context as well as the interpretive situation, the scholar's position included. The theory also foregrounds, in an exceptional way, the process perspective, which is often (but not always) lacking in linguistic theories. It does feature in some other theories of context as well, but less saliently. In the process view, meaning can be seen as experience, which means that it is processual, evolves in time, and has to do with personal and cultural backgrounds and the evolutions of subjectivity. This aspect cannot be reduced to context as product, and therefore easily gets lost from view.

A particularly disarming quality of Pepper's version is that he never claims any priority for the theory; on the contrary, both in World Hypotheses and in his contextualist theory of aesthetics, he is careful to stress that other sworld hypotheses are just as legitimate; they approach reality from different angles 
and with different world views, and in fact complement each other. Pepperian contextualism represents an early version of the idea which has later become more common in accounts of meaning and context - that of the multiplicity and heterology of foundations of meaning.

\section{Challenges for Theorizing Context}

In the above discussion on selected sexplicit ‘ theories of context, I have avoided a chronological order, as I do not want to suggest that there is a progress in thinking about context. Rather, there are ideas that live on alongside with new approaches. However, looking at the theories chronologically, one can detect for instance a shift of focus from contexts to relevance and criteria of relevance. Another development is towards more complex models of the text-context relationship. There has also been a shift from clear ontological commitments to epistemological, phenomenological and social thinking as well as more complex, multi-level, and heterological views of both context and interpretation.

Present-day theoretical thinking increasingly questions the validity of the textcontext distinction as a starting-point. In addition to post-structuralists and cultural studies scholars referred to above, for instance Juri Lotman, Paul Ricœur, and especially Jacques Derrida and other deconstructionists, have questioned the very usefulness of the distinction between the inside and the outside of text, between text and contexts. Jonathan Culler, for instance, prefers framing to context. In justifying the choice, he also gives a good summary of the problems with the term context:

\footnotetext{
But the notion of context frequently oversimplifies rather than enriches discussion, since the opposition between an act and its context seems to presume that the context is given and determines the meaning of the act. We know, of course, that things are not so simple: context is not fundamentally different from what it contextualizes; context is not given but produced; what belongs to context is determined by interpretative strategies; contexts are just as much in need of elucidation as events; and the meaning of a context is determined by events. Yet when we use the term context we slip back into the simple model it proposes.

(Culler, 1988, ix, 147-148)
}

The concept, that is, paradoxically recreates and sharpens the very division it is usually used to overcome - that between text and context.

The theories discussed above provide us with different solutions to the dichotomy problem. One solution is to bring in some aspects of the context e. g. by way of accounts of reading. A theorist of context may also resort to subsuming both text and context to a wider frame, for instance theory of action (Stierle), or introducing a 
mediating factor, for instance social cognition (van Dijk). A more radical solution to the problem Culler presents is to conceptualize both texts and contexts as parts of networks with no obvious centre (Bennett, Hall, Grossberg). In such a configuration, the interpreting subject is also presented not as something outside but as part of a network. In the latter case especially, the concept of context has to be heavily redefined, which thus hinders its communicability, and is hard to stick to in practice (cf. Felski 2011, 589). One further difference is usually invisible: the fact that the theories do not move on the same level of analysis but fail to explicate this or their consequences on other levels, e. g. methodology or ethics.

Recent cultural theories have thus underlined the need to develop an approach to texts which does not incorporate outdated and largely ideological notions of the text-context relation and which conceives of itself and its object as a complex, multi-level, processual, and perspective-dependent phenomenon. At the same time it is also obvious that one cannot just do away with the distinction altogether, even by means of alternative conceptualizations. Interpretation is always interpretation of something (Culler 1983, 73; Hulme 1984, 136). This has been the problematic point for many scholars advocating a non-dualist approach to meaning (Mailloux 1982, 27). Giving up dualism means giving up some of the answers and perspectives it made possible.

More generally even such theories that question the dichotomy have tended to slip from monism back into dualism. Culler explains this in terms of a structural necessity he sees in any attempt to conceptualise interpretation - or, in his words, in «stories of reading «. The structure of the reading process itself involves an object and a subject, it can be theorized from either perspective, and there are reasons why it should be theorized from both perspectives. For Culler, there is no in-between solution:

No compromise formulation, with the reader partly in control and the text partly in control, would accurately describe this situation, which is captured, rather, by juxtaposition of two absolute perspectives. The shift back and forth in stories of reading between readers' decisive actions and readers' automatic responses is not a mistake that could be corrected but an essential structural feature of the situation.

(Culler 1983, 73; see also Freund 1987, 152-154)

This idea of the inherent transitivity of interpretation is most likely deeply rooted in our general modes of perception and supported by both language and our everyday practices, as Pepper pointed out, so that our notions of meaning and interpretation also follow this assumption. And there is the additional fact that our tacit knowledge of the world lends ample support to this idea. As to the dilemma connected with transitivity and dualism, there are ways around it. As we have seen, some theories 
have tried to remove the dichotomies involved in the notion of context by devising alternative conceptualizations of the text-context complex.

It is easy to end up talking of contexts as if they were thing-like entities out there. In addition, contextualization is very often presented as conscious selection of points of reference from pre-existing contexts of which we are aware and have preconceptions (cf. Felski 2011, 574-578). The task in this view is to decide on the criteria of choice and to consider the consequences of the choices. This is, for many purposes, perfectly acceptable as a >discourse`, as a way of speaking of contextualization, although it will not do for a starting-point for a theory of context.

Is there still need and use for a theory of context? As the theory of articulation shows, the concept of context, in spite of its problems, can be retained by way of considerable redefinition, however with a price. But context is perhaps not something that we can have an overarching, systematic theory of in the first place. Rather, it is useful to think, following Stuart Hall, that a theory of context as such is not a goal, but to understand meaning-making, we must keep on theorizing context and contextuality.

In what follows, I take up three reasons why it is necessary and useful to keep theorizing context. First, I think it is always good and always difficult to remember that contexts are not "out there« to be picked up - instead, context is both the starting point and the end of analysis at the same time. Contexts are therefore as much in need of conceptualization as texts. This is a good guiding principle regardless of one's discipline. Second, even if we do not aim at and believe in the possibility of a theory of context, we nevertheless cannot avoid dealing with tacit notions of context. These range from the Pepperian notions supported by language and our everyday perceptions and practices to taken-for-granted assumptions often supported by our institutions. This is the reason some scholars, for instance Ansgar Nünning (Nünning 2013, 15), emphasize the need to theorize context: context theories are always »there«, and if we do not tackle them, they may and will have the kinds of influence on us that we would not like them to have. Third, contexts are often invisible, especially when they are familiar contexts! They must be teased out, and for this, comparison is perhaps the most effective method. The value of comparative approaches, indeed, is in reminding us that we tend to take our own contexts for granted and to project them on other contexts.

What is the role of the text in different theories of context? For Krieger, text is the definite centre. Textualism may be out of date ontologically, but the "power of the text « (Krieger) or the "resonance« of the text (Felski 2011, 585-588) is something that still needs to be paid attention to in theories of context. Besides, another reason to keep text in the picture is that, after all, as Pepper and radical contextualists point out, text is context for its contexts! And even in a contextualist framework, bracketing a context has its value: in some cases it may be more 
fruitful to bypass the most obvious and salient contexts and take up counterintuitive ones, as for instance New Historicists prefer to do.

As said, it is easy to be acontextual in some respect at least. In this article I have purposely drawn from several very different disciplines in an eclectic manner, bypassing the disciplinary contexts. It is good to remember that each discipline has its own requirements and uses for a theory of context.

Acknowledgement: Work on this study has been supported by the Academy of Finland.

\section{References}

Ang, len, Living Room Wars. Rethinking Media Audiences for a Postmodern World, London/New York 1996.

Bennett, Tony, The Text in Question, Southern Review 17 (1984), 118-125.

-/Janet Woollacott, Bond and Beyond. The Adventures of a Popular Hero, Basingstoke 1987.

Bex, A. R., Genre as Context, Journal of Literary Semantics 21:1 (1992), 1-16.

Bonß, Wolfgang/Rainer Hohlfeld/Regine Kollek, Kontextualität - ein neues Paradigma der Wissenschaftsanalyse?, in: W.B./R.H./R.K. (eds), Wissenschaft als Kontext - Kontexte der Wissenschaft, Hamburg 1993, 171-191.

-, Vorüberlegungen zu einem kontextualistischen Modell der Wissenschaftsentwicklung, Deutsche Zeitschrift für Philosophie 42:3 (1994), 439-454.

Cook, Guy, Transcribing Infinity. Problems of Context Representation, Journal of Pragmatics 1 (1990), 1-24.

Coulter, Jeff, Is contextualising necessarily interpretive?, Journal of Pragmatics 21 (1994), 689-698.

Culler, Jonathan, On Deconstruction, London 1983.

-, Framing the Sign. Criticism and its Institutions, Oxford 1988.

Deleuze, Gilles/Félix Guattari, Rhizome, I \& C 8 (1981), 49-71.

Derrida, Jacques, Spurs: Nietzsche’s Styles, Chicago 1978.

-, Limited Inc, Evanston, Ill. 1988.

Dervin, Brenda, Given a Context by any Other Name: Methodological Tools for Taming the Unruly Beast, in: Pertti Vakkari/Reijo Savolainen/B.D. (eds), Information Seeking in Context. Proceedings of an International Conference on Research in Information Needs, Seeking and Use in Different Contexts, 14-16 August, 1996, Tampere, Finland, London/Los Angeles 1997, 13-38.

van Dijk, Teun A., Ideology. A Multidisciplinary Approach, London/Thousand Oaks/New Delhi 1988. -, Discourse and Literature, Amsterdam/Philadelphia, Pa. 1985.

-, Discourse and Context. A Sociocognitive approach, Cambridge et al. 2008.

-, Society and Discourse. How Social Contexts Influence Text and Talk, Cambridge et al. 2009.

Felski, Rita, Context Stinks!, New Literary History 42:4 (2011), 573-591.

Freund, Elisabeth, The Return of the Reader. Reader-response Criticism, London/New York 1987. Grossberg, Lawrence, We gotta get out of this place. Popular conservatism and postmodern culture, New York/London 1992. 
-, The formations of cultural studies, in: Valda Blundell/John Shepherd/Ian Taylor (eds), Relocating cultural studies: developments in theory and research, New York/London 1993, 21-66.

-, The cultural studies crossroads blues, European Cultural Studies 1:1 (1998), 65-82.

-, Contexts of cultural studies?, in: Sirpa Leppänen/Joel Kuortti (eds), Inescapable Horizon. Culture and Context, Jyväskylä 2000, 27-49.

Hall, Stuart, Race, Articulation and Societies Structured in Dominance, in: Sociological Theories: Race and Colonialism, Paris 1980, 305-345.

-, The rediscovery of ideology: Return of the repressed in media studies, in: Michael Gurevitch et al. (eds), Culture, Society and the Media, London/New York 1982, 56-90.

-, Introduction, in: David Morley (ed.), Family Television: Cultural Power and Domestic Leisure, London 1986, 7-10.

-, Minimal Selves, in: ICA Documents 6: Identity, London 1987, 44-46.

Hyman, Lawrence W., Autonomy and Distance in a Literary Work: A New Approach to Contextualism, JAAC 31:4 (1973), 467-471.

-, The New Contextualism has Arrived: A Reply to Edward Wasiolek, Critical Inquiry 2 (1975), 380-385.

Iser, Wolfgang, Murray Krieger at Konstanz. A Colloquy Chaired by Wolfgang Iser, in: Bruce Hendricksen (ed.), Murray Krieger and Contemporary Critical Theory, New York 1986, 231-270.

Keesing, Roger, Simple Models of Complexity: The Lure of Kinship, in: Priscilla Reining (ed.), Kinship Studies in the Morgan Centennial Year, Washington 1972, 17-31.

Krieger, Murray, The New Apologists for Poetry, Minneapolis 1956.

-, Contextualism, in: Alex Preminger (ed.), Princeton Encyclopaedia of Poetry and Poetics, Princeton 1974.

Laclau, Ernesto, Politics and Ideology in Marxist Theory, London 1977.

-/Chantal Mouffe, Hegemony and Socialist Strategy. Towards a Radical Democratic Politics, London 1985.

Mailloux, Steven, Interpretive Conventions. The Reader in the Study of American Fiction, Ithaca, NY 1982.

Nünning, Ansgar, No Contextualization without Literary Theory and Concepts: Problems, Kinds and Criteria of Contextualizing Literary History, in: Elizabeth Wåghäll Nivre/Beate Schirrmacher/Claudia Egener (eds), (Re-)Contextualizing Literary and Cultural History. The Representation of the Past in Literary and Material Culture, Stockholm 2013, 13-48.

Pepper, Stephen C., World Hypotheses. A Study in Evidence [1942], Berkeley/Los Angeles 1966. Richards, Christine, Inferential pragmatics and the literary text, Poetics 9 (1985), 261-285.

Sowa, John F., Peircean Foundations for a Theory of Context, in: D. Lukose et al. (eds), Conceptual Structures: Fulfilling Peirce's Dream, Berlin et al. 1997, 41-64.

Stierle, Karlheinz, Sprechsituation, Kontext und Sprachhandlung. Zur Vorgeschichte einer Texttheorie als Handlungstheorie, in: Hans Lenk (ed.), Handlungstheorien interdisziplinär, vol. 1: Handlungslogik, formale und sprachwissenschaftliche Handlungstheorien, München 1980, 439-483.

Sutton, Walter, The Contextualist Dilemma - or Fallacy?, JAAC 17:2 (1958), 219-229.

-, Contextualist Theory and Criticism as a Social Act, JAAC 19:3 (1961), 317-325.

Taira, Teemu, Deleuze ja kontekstualismi (Deleuze and contextualism), Kulttuurintutkimus 20:4 (2003), 21-34.

Wellek, René/Austin Warren, Austin, Theory of Literature [1949], London 1961. 